\title{
Supporting adults with mental health problems through further education
}

\section{Denise Buchanan and lan Warwick}

\section{Abstract}

Aim

To explore how a college of further (tertiary) education promoted the wellbeing of adults with mental health problems.

Study design

A small-scale qualitative study of the college-related experiences of people with mental health problems.

\section{Setting}

A further (tertiary) education college in inner-city London, UK.

Methods

Fifteen students, all of whom had been diagnosed with mental health problems, were selected from a range of courses, including those attending a special cookery class, those on mainstream courses, and former-students who had studied on one of a number of courses and who may or may not have completed their courses. Data were collected through two individual semi-structured interviews.

Results

Findings focus on barriers to learning outside and inside college and how these were overcome, as well as the participants' perceived links between learning and their wellbeing.

\section{Conclusion}

The discussion highlights the necessity of a 'bridging' being established between health and education services, in order to enable adults with mental health problems to benefit from lifelong learning opportunities, in a potentially transformative way. 
Key words: mental health adult learning wellbeing transformative learning further education

\section{The context of mental health}

Enhancing mental health, which was defined by the World Health Organisation $(\mathrm{WHO}, 2014)$ as a 'state where everyone is able to realise their potential, can cope with the normal stresses of life, can work productively and fruitfully and is able to make a contribution to their community', is of increasing importance (p.60). The Lancet Commission on Global Mental Health and Sustainable Development for example, highlights the increasing burden of mental health problems across the world (Patel and Saxena, 2018).

The consequences of mental health problems are multiple - economically, societally and personally. In the UK, mental health problems cost the economy GBP 74 to GBP 99 billion per year (Stevenson and Farmer, 2017: 5). At a societal level, the rate of unemployment is greater among people with mental health problems than for the population more generally (Organisation for Economic Co-operation and Development (OECD, 2014), yet unemployment is detrimental for a person's wellbeing. Clark et al. (2018: 5) contended that unemployed people lose out not just on income but also 'something more precious - a sense of contributing, of belonging and of being wanted'. At a personal level, the stigma (Hampson et al., 2017; De Ponte et al., 2000) and the mental pain resulting from mental health problems has been found to be 'extremely difficult to adapt to - much more so than physical illness except for unremitting pain' (Layard and Clark, 2014: 5). Yet in the UK, across a one-year period, although mental health problems are reported to be experienced by one in four adults, only $25 \%$ of these adults will have received the psychological treatment they need(British Medical Association, 2017).

Moreover, the Mental Health Foundation (MHF, 2015: 57) has reported that people who are 'socioeconomically disadvantaged were 2-3 times more likely to develop mental health problems'. Such an unequal distribution reflects existing general health inequalities in the UK as identified by Marmot (2010), who outlined that people who have a lower level of socio-economic status (SES), will experience more years of ill health and die at an earlier age, than those who have a higher level of SES. This is particularly true in the area of mental health. It can be argued that people with mental 
health problems experience a triple jeopardy: coping with mental health problems, living in a low socio - economic context and having few opportunities to improve their employability (Centre for Mental Health, 2020).

\section{Adult learning and mental health}

Although there have been a number of recent studies concentrating on students at university level (Lewis and Cardwell, 2019; McManus and Gunnell, 2019; Thorley, 2017; Usher, 2019), these often look at students aged 25 and under. Far fewer studies have examined a wider age range of students in further and adult education (Waller et al., 2018). Against this background, the role that further education can potentially play in improving the lives of people with mental health problems, is explored in this article and the term learning or education is used to refer to any learning that occurs within a structured setting. In this study, the term Further Education (FE) college is used to refer to post-16 colleges which teach both vocational and academic courses. However, in the UK, FE can also include other adult learning provisions such as sixth form centres (for 16-18-year olds), community learning centres and prison education.

Previous educational research has highlighted that adult classroom learning can help the wellbeing of individuals and their families and communities (Duckworth, 2017; Feinstein et al., 2008; Field, 2012; Buchanan, 2014; Schuller and Watson, 2011), although it can also negatively impact people's lives (Bourdieu, 1998; Reay, 2003; Waller et al., 2011). With respect to adults with mental health problems, relatively little research has been carried out to identify the ways in which they experience formal learning, although three key studies address this: James and Talbot-Strettle (2009); Lewis (2014) and Fernando et al. (2014). In each study the authors reported there to be strong evidence to support the idea that for adults with mental health problems, engaging in learning yielded several benefits. These included increased levels of self-determination and personal responsibility, learning new skills, and increased feelings of hopefulness, confidence and sociability.

Nonetheless, the three studies also highlighted certain barriers to learning that needed to be overcome, in order for the adults to fully engage in their learning. Wallace (2005: 91) described a barrier to learning as occurring when 'something occupies our mind, preventing us from focusing the necessary attention on what 
needs to be learnt'. The barriers identified in the three studies referred to above, included experiencing difficulties caused by medications, feeling socially isolated and lacking social support. Significantly, the main cause they identified for students leaving college prematurely, was the lack of support they received at college rather than their mental health problems. Conversely, James and Talbot-Strettle (2009: 2) found that receiving emotional and practical support from 'one or two key people' appeared to be crucial. Also, crucial, was a partnership being forged between the college and the health providers; such a partnership greatly increased the chances of these learners being able to cope with the demands of attending college.

However, despite the benefits of classroom learning for adults with mental health problems, funding for adult courses has consistently fallen and few mental health policies exist in relation to adult learning. In addition, suggestions made to counteract this lack of policy in FE (Association of Colleges, 2017; Learning and Work Institute, 2017), have not been acted upon.

Given this background, the aim of this study was to explore how learning might influence a sense of wellbeing for adults with mental health problems and in doing so, examine the links between learning, wellbeing and personal transformation. The overarching research questions were:

1. What is the wider societal context for adults with mental health problems returning to formal learning?

2. Considering the relationship between societal factors and mental health, what are the perceptions of adults with mental health problems regarding the influence of classroom learning on their wellbeing?

3. In what ways can their experiences and perceptions be understood with reference to Mezirow's theory of transformative learning?

In this article - and building on the argument by James and Talbot-Strettle (2009) that a partnership between college and health services should be forged to best support the wellbeing of students with mental health problems - we report how this played out between one inner London FE college and the local health provider. Conceptually the study was informed by the theory of transformative learning (TL), proposed by Mezirow (2009), which has been popular among adult learning 
theorists. Specifically, Mezirow theorised that adults returning to formal learning could experience transformation of their:

... problematic frames of reference...sets of assumption and expectation to make them (become) more inclusive, discriminating, open, reflective and emotionally able to change (p.92).

These 'frames of reference' refer to a person's habitual ways of thinking that have been developed from infancy, as a result of one's family and cultural upbringing. By re-engaging with learning as an adult, Mezirow postulated that these frames could be challenged, within an environment that encouraged critical discourse with others and critical reflection. This could lead to a change in their 'way of knowing' (Kegan, 2009: 44), leading to transformative changes in how a person came to view themselves, the world and their position in the world.

The educational process through which such changes might occur, Mezirow suggested was one in which the student developed a trusting relationship with their teacher $-a$ teacher who demonstrated acceptance, respect and positive regard towards the learner (see also Rogers, 1951). However Mezirow (2003: 60) did acknowledge that a person cannot benefit fully from such learning if they are, 'Hungry, desperate, homeless, sick, destitute and intimidated'; that is, factors which are most usually external to an educational setting.

\section{Methodology}

\section{Approach}

A broadly subjectivist approach (Cohen et al., 2011; Creswell, 2013) guided the study, the underlying assumptions being that people construed and acted in relation to the world in somewhat different ways. Accordingly, the subjective meanings of participants were interpreted and identified, with the study being idiographic in character.

\section{Design}

The study was exploratory and relatively small in scale, with qualitative information being collected. Fieldwork consisted of five phases: 
1. Gaining permission to carry out the study, from the college and health care provider.

2. A first round of interviews carried out with the participants who elected to take part in the study. The interviews were audio-recorded and transcribed.

3. Thematic analysis to draw out preliminary themes related to learning and wellbeing.

4. A second round of interviews which were also recorded and transcribed.

5. A final round of thematic analysis took place in order to identify the set of overarching sub-themes and themes.

\section{Literature review}

A three-phase approach was adopted for the literature review - a literature search, literature analysis and literature synthesis. Each phase was guided by the conceptual framework of TL, drawing on reports and academic texts relating to mental health in conjunction with education.

\section{Fieldwork}

\section{Sampling/ selection}

The site of the study was London UK, of which the setting was an inner-city FE college. This college was selected because the first author (DB) had taught there, running a cookery class for students diagnosed with mental health problems. The college had won numerous national awards for its provision for students with mental health problems.

Fifteen students aged between 18 and 60 years, all of whom had mental health problems (ranging from depression to schizophrenia), were recruited voluntarily. Twelve participants self-identified as being from Black, Asian or minority ethnic groups and three self-identified as being White British. Students were recruited from a range of courses: those attending a cookery course that was only open to students with mental health problems; those on mainstream course and former-students who had studied on one of a number of courses and who may or may not have completed their courses.

Informed by the Economic and Social Research Council (2014), recruitment of the participants involved a preliminary discussion with the Mental Health Advisers 
(MHAs), so that students were only invited to take part in the study if they were perceived to be well enough. The MHAs concerned worked in both the college and the local mental health unit as part of a joint initiative between the college and the National Health Service (NHS). Students who were under the protection of the Mental Capacity Act (2005) were not invited to take part in the study.

\section{Data collection}

Data were collected through two individual audio-recorded semi-structured interviews per participant. During the first interview participants were asked questions about their background, how and why they had decided to attend college, as well as of their recent classroom experiences with both their teachers and fellow students. Second interviews were informed by themes that emerged during a preliminary analysis of the data. For instance, questions were asked regarding the differences in the type of support offered by the academic college staff, in relation to the non-academic staff and how they felt that their college experiences differed from their health care experiences. The first author conducted the interviews at the college in an office adjacent to the MHA's office. Interviews lasted 45-60 minutes.

\section{Data analysis}

All the interviews were fully transcribed and an iterative approach to analysis was adopted (Braun and Clarke, 2006). This began by repeatedly reading the scripts and writing emergent codes (e.g. socialising; confidence), onto the transcripts. Codes were collated into tables and then mind maps were developed in order to link the codes and develop possible sub-themes. For instance, the sub-themes of 'disorganised college; poor teaching and lack of motivated peers' merged into one of the main themes, 'barriers to learning inside college'. This process was replicated for all the individuals after which the main themes, outlined below, emerged. Underpinning the analysis and providing sensitising concepts (Strauss, 1987), was the theory of TL (Mezirow, 2009).

\section{Ethics}

Approval for this study was given by the university and the East London NHS Foundation as most of the participants had joined the college via NHS services; the NHS ethical approval stipulated that participants should not be asked directly about 
their clinical experiences. As the participants were classed as 'vulnerable' (BERA, 2018), the inclusion and exclusion criteria was established in conjunction with the MHAs. The MHAs agreed to act as gatekeepers for the study which proved to be invaluable as ethical issues arose during some of the interviews, such as three participants mentioning their recent suicidal thoughts. A clause had been included in the consent forms, that should participants become distressed during the interviews, the MHAs would be available to meet with them afterwards, to ameliorate possible harm. Although some participants did become distressed during their interviews, they declined the offer to terminate their interviews prematurely or meet with the MHAs. Afterwards all, except one $\left(\right.$ George $\left.^{1}\right)$, reported that they did not feel harmed from taking part in the study. George said that the interviews had evoked some painful memories for him.

\section{Findings}

Four main findings were identified:

1. Barriers to learning outside college

2. Barriers to learning inside college

3. How barriers could be overcome

4. How classroom learning could influence wellbeing

Perhaps due to the small-scale nature of the study, the issues outlined by participants did not appear to relate directly to demographic characteristics (such as age or ethnicity) but rather more to their mental health problems and experiences outside and inside college.

\section{Barriers to learning outside college}

\section{Mental health problems}

Thirteen participants recounted traumatic memories of being acutely unwell and hospitalised, three of whom spoke of experiencing recent suicidal thoughts, which was reported to the gatekeepers. Interestingly these three people were all formerstudents who were currently not involved in any educational or vocational programmes.

\footnotetext{
${ }^{1}$ All names are anonymised
} 
A common worry among participants was fearing a relapse of their mental health problems, which could compromise their college attendance. Another worry concerned how participants could cope within a college setting, with the negative side effects of their medication.

A few participants mentioned that they did not consider themselves to be like 'normal' people, due to their mental health problems. As Louise highlighted when she spoke of her life before her illness:

So, I had a life, I had a job...I was a normal person. Becoming a patient, I thought I was a nobody...

Poverty

Participants noted there to be certain underlying social and material requirements that affected their engagement - such as living in poverty, which for some necessitated the use of food banks ${ }^{2}$. For six participants who had been homeless, seeking shelter each night had been all-consuming mentally, which harmed their mental health problems. All participants feared the prospect of their welfare support being withdrawn suddenly and so being forced to find employment, despite their mental health problems. Yet, all participants wished to be well enough to be in employment, although moving from welfare benefits to employment could cause its own problems, as Danny stated:

I'm so relieved it is weekly pay (in his new job) as there's a big gap money wise between the (welfare) benefits stopping. The first month is going to be tough financially and it will be bloody hard having to pay for gas and electric and buy food.

\section{Barriers to learning inside college}

\section{Mental health problems}

All participants felt that their mental health problems were a barrier to their learning at times within the classroom. They reported concentration problems due to experiencing fatigue following disrupted sleep, low moods or intrusive auditory hallucinations.

Classroom experiences

\footnotetext{
${ }^{2}$ This is a place where people in need are supplied with free basic provisions, donated by the public.
} 
The barriers experienced by participants on accredited courses included teachers not turning up, course work being lost and experiencing delays in the provision of required dyslexia support. Poor quality teaching meant that June had to leave her history course prematurely and, as Charlie noted: 'Sometimes, it's a bit boring and if there's a lot of waffle, I lose my focus'. However, whilst a few participants highlighted poor teaching, more general views were succinctly summed up by Prem: 'My teacher is wicked, he's the best teacher ever as he really brings this subject alive'.

Another internal barrier for some, was feeling emotionally unsafe in the classroom, leading to a lack of engagement within their class, as June expressed: 'You need to like your teacher in order to like, feel safe. You need to feel like, you're wanted'.

Similarly, Gordon highlighted how not feeling safe affected his behaviour in the classroom:

I had an experience on one occasion in my teacher training class where people were making fun of mental health students and it just immobilised me. Like, a part of me wanted to say, 'Hold on, l've got mental health problems', but part of me was scared to, as they might make fun of me.

Gordon stated that the teacher did not challenge these comments.

A sense of fear relating to the stigma of having mental health problems was shared by other students. Daisy spoke of not wanting her peers to know that she had mental health problems, particularly as her three children had been adopted due to these problems. Joan was worried that people would think she was violent as she experienced auditory hallucinations, stating: '.. . because I think people might think I might become a bit violent but l'm peace loving'.

\section{How barriers could be overcome}

\section{Good teaching}

In contrast to the difficulties experienced due to poor teaching, several participants spoke of how a 'good' teacher, who was patient and accommodating in relation to their mental health problems, had the potential to inspire and challenge them.

Good support

However, on its own good teaching alone was not enough for some participants to remain on their study programme as they felt that it was the more specific support 
received from the MHAs that enabled them to continue. For example, regarding barriers experienced due to poverty, the MHAs were vital in ensuring that students knew who to contact to find out about financial assistance. Regarding barriers within the college, the MHAs liaised with specific teachers to discuss how best to respond to students' difficulties. Additionally, if a student had a mental health relapse, the MHAs kept in contact with them during their absence and informed the teacher of their progress. This level of targeted support from MHAs was reported as being invaluable, as Nelson explained:

Kevin (the MHA) is experienced in mental health, and he literally took me to the induction and introduced me to the teachers and told them I would need assistance; it was such a good backup system.

The key elements of support provided by MHAs, which participants reported, included: meeting with students on a one to one basis and so offering tailored support; having a thorough understanding of mental health problems, which was superior to that of even well informed teachers; enabling students to progress incrementally ('stepping stones' as Simon called it), as well as intervening when a student was experiencing difficulties within the classroom. Their contribution was summed up by June as she said:

The MHAs give you a safe place to talk, because I think with teachers they're always in a rush and they always have things to do. But Kevin and Sarah were like, they're there for you and your personal needs.

\section{How classroom learning could influence wellbeing}

Participants stated that when they were given the necessary help to overcome external and internal challenges to study, they benefited in a number of way (outlined in Buchanan, 2019). This included enjoying learning, feeling more hopeful and feeling absorbed in and stimulated by both studying and mixing socially.

Moreover, the college context provided benefits over and above those provided by the health service, For example, Orla felt that the hospital groups she had previously attended were not comparable to her college classes in which she felt she was 'definitely learning', and spoke of becoming more reflective about herself. Louise stated that learning offered something different from therapy: 
In hospital you are all pumped up with medication as your head is heavy, but when training, I feel normal. Group therapy? You are still being treated like a patient.

Daisy spoke of now feeling proud that she had a 'role in society', saying that college enabled her to get a certificate and prepare her for work. Reuben, who had left his course prematurely due to being ridiculed by other students because of his mental health problems, maintained that his time at college had been useful, as he said:

Before I went to college, I thought l'm just going to sit around doing nothing my whole life. Going to college was like the first ever step that pushed me... Education is a foundation for everyone's minds and so it helps people regulate their mind and helps them get along.

A few participants also noted that taking part in classes had contributed to them experiencing intellectual growth and several alluded to experiencing changes in how they viewed themselves and their position in the world. Such significant changes were expressed by Santosh who said:

My friends are amazed; I have gained so much confidence and now I am not intimidated by friends who are lawyers or doctors. What I have to say to them is as valuable as what they have to say to me. I know who I am now. I have self-respect now.

Such changes were echoed by Louise who said:

Becoming a patient, I thought I was nobody....in the hospital I'm being treated as if I'm heavily sedated or I'm still sick, but in college I think I'm being treated as normal. I have a sense of purpose that I can actually do something. It builds me up.

The ways in which classroom learning appeared to significantly change how several of the participants viewed themselves and the world, will be discussed below in relation to Mezirow's theory of transformative learning.

\section{Discussion}

\section{Prior research}

Many of the findings in this study resonate with previous work in this area (Fernando et al., 2014; James and Talbot-Strettle, 2009; Lewis, 2014). The findings confirmed that while adults with mental health problems may encounter barriers to taking part in adult education, being able to engage with a curriculum through supportive teaching, positively influenced their sense of wellbeing. Moreover, this study extended prior understandings of supporting such students. 


\section{Transformative learning?}

Findings provide some support for ideas associated with TL proposed by Mezirow (2009). A few participants reported significant changes in their sense of self and how they viewed the world as a result of their thinking having been challenged and expanded. Yet the findings also pointed to some limitations in relation to TL, one being that among the participants who could be said to have experienced a degree of personal transformation, there appeared to be variations about the nature, breadth and depth of it. For example, Reuben's account suggested significant intellectual development, whereas for Daisy, she chiefly reported experiencing change in her sense of self. Also, identifying intellectual changes proved to be harder than identifying changes in a person's sense of self, which suggests that TL may be too abstract as a concept. It could likewise be argued, as Howie and Bagnall (2013) have done, that for those who did appear to have experienced intellectual changes, these changes may merely have reflected the academic level of the courses they were studying on and which they had had the capabilities to enrol onto in the first place. Equally, it may be that in order to engage in critical discourse, which Mezirow proposed was crucial for TL to happen, a person must already have a high enough level of cognitive functioning to enable them to benefit from such dialogue. However, it was difficult to ascertain whether these experiences of transformation were longlasting, although the accounts of the former-students suggested that the changes they had undergone in their thinking whilst at college, had remained.

As noted, although Mezirow (2003) acknowledged (albeit in a somewhat limited way) that a person cannot benefit fully from education if hungry, desperate, homeless or unwell, or who feel intimidated, for those students in this study who had been in such circumstances, these were especially relevant. Participants often highlighted how such adversity impacted on three aspects of education: their ability to attend college, their ability to concentrate in class and their ability financially to consider further academic studies. Despite this, much of the existing literature on TL appears to assume that the social and material conditions in which the students live will already be adequate prior to beginning their courses. This assumption may be made because most of the original research carried out by Mezirow took place among North American middle-class students, yet as shown above, this was not the case for the students in our study. In light of this, we would suggest that the theory of TL 
needs refinement so as to be more explicit about this issue. We also urge educators to avoid making such mistaken assumptions, as it may be that for students with mental health problems, educational provision will also need to be adapted to their social and material circumstances.

\section{The necessity of partnerships}

This study identified the nature of adaptation and support that vulnerable students required in order to attend college and make the most of the learning opportunities offered there. Notably, the support provided by the MHAs helped to ensure that participants completed their courses. Had this personalised support not been in place, several participants stated that they would have left their courses prematurely. This level of support provided by the MHAs resonate with ideas associated with accompaniment (Green and Christian, 1998; Távara et al., 2017; Watkins, 2015), which propose that 'the intentional presence of another, committed to working alongside, deeply listening to, and collectively responding with action against systems of oppression' can in itself be transformative (Wilkinson and D'Angelo, 2019: 151). Among study participants, poverty, a sense of stigma and a lack of agency associated with mental health problems, were ameliorated by forms of supportive professional practice encountered through the college. When such personalised support was in place, being in a college environment could offer participants something that was different and intrinsically more life affirming than that offered to them within a health setting.

Regarding the implications of the study findings, the increased participation of students with mental health problems may well be made possible only if they feel materially, physically, and emotionally secure, and if tailored adult provision is made available and accessible. In addition, there may be advantages if the employment of college-based MHAs is made mandatory as it was their understandings of the rather different cultures and practices of health and education that enabled the students to 'bridge' these contexts. Such 'bridging' may well require new ways of commissioning partnerships between education and mental health services, so as to maximise the synergistic links between good education, health and wellbeing; a synergy receiving greater global attention (UNESCO and Bokova, 2014). This change, bridging health 
and education, could shift mental health from being either that of prevention or treatment, to attempting to address both prevention and treatment concurrently.

In summary, we argue for improved 'bridging' or complementarity between health and education to enable adult education to be available, accessible, acceptable and adaptable (Tomasevski, 2006; McCowan, 2012) to those with mental health problems. To conclude, we revisit a quote from Louise who especially valued the ways in which her college experience had contributed to her ability to realise her potential:

Becoming a patient, I thought I was nobody....in the hospital I'm being treated as if I'm heavily sedated or I'm still sick, but in college I think I'm being treated as normal. I have a sense of purpose that I can actually do something. It builds me up.

\section{References}

Association of Colleges. (2017) AoC survey on students with mental health conditions in Further Education. London: Association of Colleges,.

BERA. (2018) Ethical Guidelines for Educational Research. Available at: https://www.bera.ac.uk/wpcontent/uploads/2018/06/BERA-Ethical-Guidelines-for-EducationalResearch 4thEdn 2018.pdf?noredirect=1.

Bourdieu P. (1998) Acts of resistance Cambridge: Policy Press.

Braun V and Clarke V. (2006) Using thematic analysis in psychology. Qualitative Research in Psychology 3: 77-101.

British Medical Association. (2017) Breaking down barriers - the challenge of improving mental health outcome. London: British Medical Association.

Buchanan D. (2014) A phenomenological study highlighting the voices of students with mental health difficulties concerning barriers to classroom learning,. Journal of Further and Higher Education 38: 283-446.

Buchanan D. (2019) 'Five years ago I was on suicide watch...now I'm in college gaining a qualification'. Journal of Further and Higher Education: 1-13.

Centre for Mental Health. (2020) Briefing 1: Determinants of mental health. Commission for Equality in Mental Health. London: Centre for Mental Health.

Clark A, Fleche S, Layard R, et al. (2018) The Origins of Happiness. The Science of Well-Being over the Life Course, Oxford and Princeton: Princeton University Press.

Cohen L, Manion L and Morrison K. (2011) Research methods in Education, Oxford: UK: Routledge.

Creswell JW. (2013) Qualitative inquiry and research design : choosing among five approaches Los Angeles ; London: SAGE.

De Ponte P, Bird L and Wright S. (2000) Pull yourself together!: A survey of the stigma and discrimination faced by people who experience mental distress. London: UK: The Mental Health Foundation.

Duckworth V. (2017) Sharing transformational approaches to teaching and learning. Further education Transforming lives and communities. Lancashire, UK: UCU.

Economic and Social Research Council. (2014) Framework for research ethics. Available at: http://www.esrc.ac.uk/about-esrc/information/research-ethics.aspx. 
Feinstein L, Budge D, Vorhaus J, et al. (2008) The social and personal benefits of learning: a summary of key research findings London: Centre for Research on the Wider Benefits of Learning, Institute of Education, .

Fernando S, King A and Loney D. (2014) Helping Them Help Themselves: Supported Adult Education for Persons Living with Mental Illness. Canadian Journal for the Study of Adult Education 27: 15-28.

Field J. (2012) Is Lifelong Learning Making a Difference? Research-Based Evidence on the Impact of Adult Learning. In: Aspin D (ed) Second International Handbook of Lifelong Learning. London: Springer 887-897.

Green M and Christian C. (1998) Accompanying young people on their spiritual quest, London: National Society/Church House Publishing.

Hampson ME, Watt BD and Hicks RE. (2017) Changing hearts and minds: The importance of formal education in reducing stigma associated with mental health conditions Health Education Journal 77: 198-211.

Howie P and Bagnall R. (2013) A beautiful metaphor: transformative learning theory International Journal of Lifelong Education 32: 816-836.

James K and Talbot-Strettle L. (2009) 'I'd turn up even if I won the lottery!' Research into the factors that impact on attendance, retention and achievement of learners with mental health difficulties. Leicester: Quality Improvement Agency: Improver Advisor Service.

Kegan R. (2009) What 'form' transforms? A constructive-developmental approach to transformative learning. In: Illeris K (ed) Contemporary theories of learning : learning theorists - in their own words London: Routledge, 35-52.

Layard R and Clark D. (2014) Thrive: The Power of Evidence-Based Psychological Therapies, Milton Keynes: UK: Penguin Random House.

Learning and Work Institute. (2017) Healthy, Wealthy and Wise: The impact of adult learning across the UK. Leicester: National Learning and Work Institute.

Lewis EG and Cardwell JM. (2019) A comparative study of mental health and wellbeing among UK students on professional degree programmes. Journal of Further and Higher Education 43: 1226-1238.

Lewis L. (2014) Responding to the mental health and well-being agenda in adult community learning. Research in Post-Compulsory Education 19: 357-377.

Marmot M. (2010) Fair society, healthy lives : the Marmot Review : strategic review of health inequalities in England post-2010. London: GOV.UK.

McCowan T. (2012) Is There A Universal Right To Higher Education? British Journal of Educational Studies 60: 111-128.

McManus S and Gunnell D. (2019) Trends in mental health, non-suicidal self-harm and suicide attempts in 16-24-year old students and non-students in England, 2000-2014. Social Psychiatry and Psychiatric Epidemiology 55: 125-128.

Mental Capacity Act. (2005) Mental Capacity Act Available at: http://ethicsguidebook.ac.uk/MentalCapacity-Act-118.

Mezirow J. (2003) Transformative Learning as Discourse. Journal of Transformative Education 1: 5863.

Mezirow J. (2009) An overview on transformative learning. In: Illeris K (ed) Contemporary theories of learning : learning theorists - in their own words. Oxford: UK: Routledge, 90-105.

MHF. (2015) Fundamental Facts About Mental Health In: Foundation MH (ed). London: Mental Health Foundation.

OECD. (2014) Mental Health and Work: United Kingdom. Paris: France: Organisation for Economic Co-operation and Development.

Patel V and Saxena S, et al. (2018) The Lancet Commission on global mental health and sustainable development. The Lancet: 1553-1598. 
Reay D. (2003) A risky business? Mature working-class women students and access to higher education. Gender and Education 15: 301-317.

Rogers CR. (1951) Client-centered therapy : its current practice, implications and theory London: Constable.

Schuller T and Watson D. (2011) Learning through life: inquiry into the future of lifelong learning. Leicester: NIACE.

Stevenson D and Farmer P. (2017) Thriving at Work: a review of mental health and employers. London: Department for Work and Pensions and the Department of Health.

Strauss AL. (1987) Qualitative analysis for social scientists, Thousand Oaks: CA: Sage.

Távara G, Brinton Lykes M and Crosby A. (2017) Standing in Between: The Healing Praxis of Mayan Women Intermediaries in Post-Genocide Guatemala. Women and Therapy 41: 30-51.

Thorley C. (2017) Not by degrees: Improving student mental health in the UK's universities,. London: IPPR.

Tomasevski K. (2006) Human Rights Obligations in Education: the A-4 Scheme, Nijmegen: Wolf Legal Publishers.

UNESCO and Bokova I. (2014) Teaching and learning: Achieving quality for all; EFA global monitoring report, 2013-2014: UNESCO Publishing.

Usher W. (2019) Living in quiet desperation: The mental health epidemic in Australia's higher education Health Education Journal 79: 138-151.

Wallace S. (2005) Teaching and supporting learning in further education : meeting the FENTO standards Exeter: Learning Matters.

Waller R, Bovill H and Pitt R. (2011) Parents, partners and peers: bearing the hidden costs of lifelong learning. International Journal of Lifelong Education 30: 547-564.

Waller R, Hodge S, Holford J, et al. (2018) Adult education, mental health and mental wellbeing. International Journal of Lifelong Education, 37: 397-400.

Watkins M. (2015) Psychosocial Accompaniment. Journal of Social and Political Psychology 3: 324341.

WHO. (2014) Mental health: a state of well-being. Available at: http://www.who.int/features/factfiles/mental health/en/.

Wilkinson M and D'Angelo K. (2019) Community-based accompaniment \& social work-A complementary approach to social action. Journal of Community Practice 27: 151-167. 